\title{
DiminishING
}

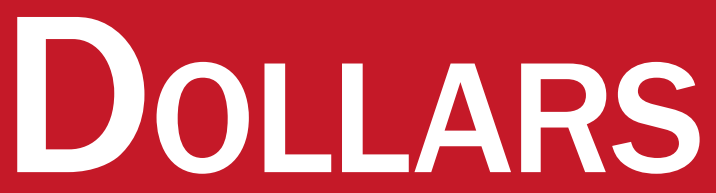

\section{The Impact of the 2008 Financial Crisis on the Field of Social Justice Philanthropy}

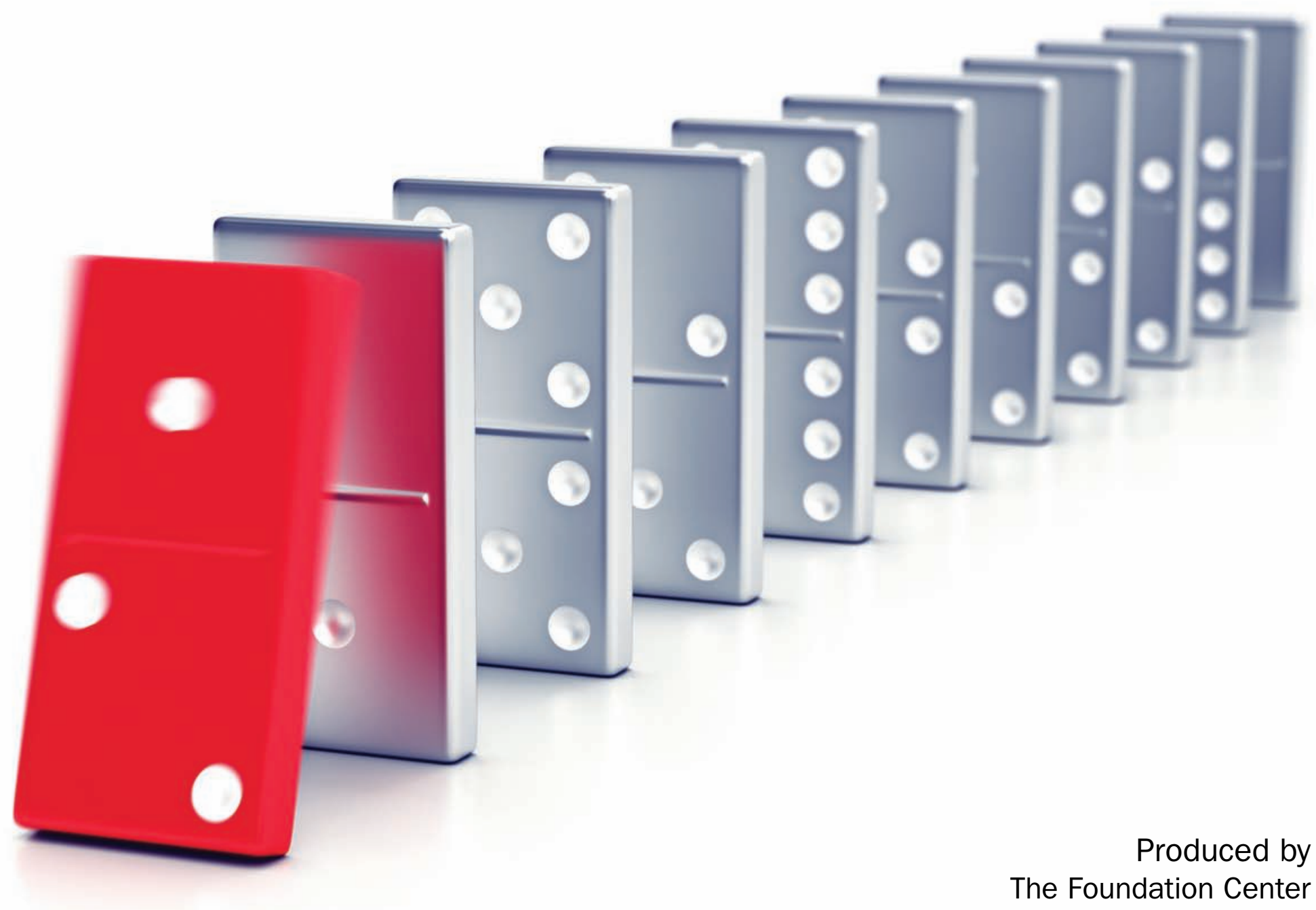




\section{DIMINISHING}

\section{Dollars}

The Impact of the 2008 Financial Crisis on the Field of Social Justice Philanthropy

Sara K. Gould

Atlantic Philanthropies Senior Fellow 


\section{CONTRIBUTING STAFF}

\begin{tabular}{|c|c|}
\hline Brielle Bryan_ & C Consultant \\
\hline Larry Carlin & Application Development Manager \\
\hline Douglas Eng & Special Data Projects Associate \\
\hline Bradley Hill & Research Assistant \\
\hline Christine Innamorato & Production Manager \\
\hline Desarae Jones & _ Research Assistant \\
\hline Ruth Kovacs_ & Manager, Recipient Authority File \\
\hline Nicholas Kramer & Senior Associate, Special Data Project Unit \\
\hline Kimberly Lorch & Research Assistant \\
\hline Lawrence T. McGill & Vice President for Research \\
\hline Jasmine McGinnis & Research Assistant \\
\hline Reina Mukai_ & Senior Research Associate \\
\hline Matthew Ross & Manager of Special Data Projects \\
\hline Grace Sato & Research Data Assistant \\
\hline Vanessa Schnaidt & Director of Communications \\
\hline Cicely Weathington & Research Assistant \\
\hline David Wolcheck & Research Associate \\
\hline
\end{tabular}

\section{ABOUT THE FOUNDATION CENTER}

Established in 1956, the Foundation Center is the leading source of information about philanthropy worldwide. Through data, analysis, and training, it connects people who want to change the world to the resources they need to succeed. The Center maintains the most comprehensive database on U.S. and, increasingly, global grantmakers and their grants — a robust, accessible knowledge bank for the sector. It also operates research, education, and training programs designed to advance knowledge of philanthropy at every level. Thousands of people visit the Center's web site each day and are served in its five regional library/learning centers and its network of more than 450 funding information centers located in public libraries, community foundations, and educational institutions nationwide and around the world. For more information, please visit foundationcenter.org or call (212) 620-4230.

\section{ACKNOWLEDGEMENTS}

This study was made possible by a working partnership between the Cricket Island Foundation (Elizabeth Sak), the Foundation Center (Sara Gould, Larry McGill, Reina Mukai, Grace Sato), the National Committee for Responsive Philanthropy (Aaron Dorfman), the Robert F. Wagner School of Public Service at New York University (Capstone Team: Shangshang Chen, Didi Ilunga, Kaity Ng, Kelly Richardson, Amita Swadhin), and the Social Justice Philanthropy Collaborative (Jason Franklin). Sheila Aminmadani served as project coordinator, and Christine Harris assisted with the forecasting section.

We are deeply grateful to the Cricket Island Foundation, the Ford Foundation, and the Edward W. Hazen Foundation for providing funding for the study.

(C) 2011 by the Foundation Center. All rights reserved. Printed and bound in the United States of America. ISBN 978-1-59542-367-2 


\section{Contents}

EXECUTIVE SUMMARY vi

INTRODUCTION _ 1

The Context__ 1

Purpose of the Study _ 2

Overview of the Report __ 2

DESIGN OF THE STUDY ___ 3

Methodology ___ 3

HISTORICAL DATA (2005-2009) ON ASSETS, SPENDING, GIVING, AND SOCIAL JUSTICE GIVING___ 4

FOUNDATION STRATEGY IN THE IMMEDIATE AFTERMATH OF THE DOWNTURN __ 11

LOOKING FORWARD: PROJECTIONS IN GRANTMAKING TRENDS AND ASSET LEVELS (2008-2015) _ 13

Methodology

General Trends in Asset Levels (2008-2015) _ 14

Unintentional Asset Depletion___ 16

Grantmaking Trends (2008-2015) __ 16

CONCLUSION _ 19

Findings___ 19

Recommendations _ 19

APPENDIX A: LIST OF FOUNDATIONS IN HISTORICAL ANALYSIS _ 21

APPENDIX B: LIST OF U.S. GEOGRAPHIC REGIONS AS DEFINED BY THE FOUNDATION CENTER ___ 22

APPENDIX C: FOUNDATIONS INCLUDED IN FORECASTING TO 2015 23

APPENDIX D: INTERVIEW PROTOCOL ___ 24

APPENDIX E: CONFIDENTIALITY STATEMENT ___ 26

APPENDIX F: CRITERIA FOR CONFIDENCE CATEGORIES ___ 27 


\section{Tables and Figures}

Figure 1. Total Assets (millions), 2005-2009 5

Figure 2. Average Assets by Size Subgroup (millions), 2005-2009__ 5

Figure 3. Percentage Change of Average Assets by Size Subgroup, 2005-2009_6

Figure 4. Total Expenditure (millions), 2005-2009_ 6

Figure 5. Average Expenditure by Size Subgroup (millions), 2005-2009__ 6

Figure 6. Percentage Changes in Average Expenditure by Size Subgroup, 2005-2009_ 7

Figure 7. Total Giving (millions), 2005-2009___ 7

Figure 8. Average Giving by Size Subgroup (millions), 2005-2009__ 8

Figure 9. Percentage Change of Average Giving by Size Subgroup, 2005-2009_ 8

Figure 10. Giving/Expenditure Ratio (millions), 2005-2009__ 9

Figure 11. Giving/Expenditure Ratio by Size Subgroup, 2005-2009___

Figure 12. Average Percentage of Social Justice Giving of Entire Sample ___ 9

Figure 13. Size Distribution by Number of Foundations in the Sample___ 14

Figure 14. All Funders Aggregate Asset Values (millions) ___ 14

Figure 15. Small Funders (<50m) Aggregate Asset Values (millions)

Figure 16. Medium Funders (50-200m) Aggregate Asset Values (millions) ___ 15

Figure 17. Large Funders (>200m) Aggregate Asset Values (millions) ___ 15

Figure 18. Distribution of the Funders in the Projections of Assets ___ 16

Figure 19. All Funders Aggregate Grantmaking (millions)___ 16

Figure 20. Small Funders (<50m) Aggregate Grantmaking (millions) ___ 17

Figure 21. Medium Funders (50-200m) Aggregate Grantmaking (millions) ___ 17

Figure 22. Large Funders ( $>200 \mathrm{~m}$ ) Aggregate Grantmaking (millions) ___ 18

Figure 23. Distribution of the Funders in the Projections of Grantmaking Expenditures___ 18

Table 1. Change in Assets from 2007 to 2008

Table 2. Descriptive Statistics of Three Subgroups by 2009 Assets __ 5

Table 3. Average Percentage of Social Justice Giving by Subgroup ___ 10 


\section{Executive Summary}

In the second half of 2008 , the United States experienced a severe economic downturn. Often called the Global Financial Crisis, it is considered by many economists to be the worst financial crisis since the Great Depression. In the United States, the effects of the downturn were felt across every sector of our economy and society.
Philanthropy was, of course, no exception; according to Foundation Center data, in 2008, U.S. foundation assets declined a record 17.2 percent.

In 2010, concerned that the downturn would impact future levels of funding in social justice philanthropy for years to come, the Cricket Island Foundation (CIF) decided to undertake an analysis of social justice funding through 2015 and to make this vital information available to both grantees and funders. CIF secured a Capstone Team of students from the Robert F. Wagner School of Public Service at New York University (NYU) to conduct the analysis, and reached out to the Social Justice Philanthropy Collaborative (SJPC) for assistance in securing interviews with national funders. Together, CIF and SJPC enlisted the Foundation Center and the National Committee for Responsive Philanthropy (NCRP) as additional partners. The project was managed overall by CIF, while NCRP served as fiscal sponsor.

This report both identifies the major immediate impacts of the 2008 financial crisis on social justice philanthropy and takes a look into the future. It aims to provide new and useful information to both funders and nonprofit organizations seeking funds. Foundations active in the social justice arena can use this information to strategize, inside their institutions and with their peers, about ways to bring additional, urgently needed funding to the field. For nonprofits, the information presented here is crucial to their planning efforts and their ability overall to weather the storm.

This report examines historical data (from 2005 to 2009) to discover trends in assets, spending, and giving for 54 foundations known to be active in the social justice sector and that award $\$ 100$ million or less annually, principally from endowment. These foundations accounted for about one-quarter of all documented social justice grantmaking in 2009. It describes the major strategies used by a subset of 23 foundations to cope with depleted assets in the period immediately following the downturn, and then presents projections to 2015 for assets and grantmaking levels of 18 of these foundations. The report concludes with a summary of findings, limitations, and suggestions for further study.

Key findings of the study indicate that:

- Unless the field sees five years of above-average investment returns, social justice grantmaking levels in 2015 will remain below 2008 levels. For the subset of 18 foundations, at an average (7 percent) rate of return, grantmaking in 2015 is projected to be 5.5 percent less than grantmaking in 2008 . Given the slow economic recovery now underway and the recent volatility and uncertainty in the markets, this finding is particularly worrisome. Also, social justice grantmaking is a portion of total grantmaking for these foundations, and it is not possible to know how their priorities might change with more limited funds.

- Small foundations (less than $\$ 50$ million in assets) will continue to struggle to recover from the economic downturn. At an average (7 percent) rate of return, grantmaking levels of six small foundations studied are projected to be 17 percent less in 2015 than in 2008. Small foundations must spend less in grantmaking to avoid depleting their assets. This finding deserves particular note because of the very heavy reliance on small foundations by local, community-based nonprofits engaged in social justice work. 
- In 2009, grantmaking decreased to below 2007 levels, with small foundations experiencing the largest drop. In interviews with 18 foundations, however, senior officials of nearly every one reported taking actions (e.g., increasing payout and decreasing other expenditures) to maintain current grantmaking levels despite depleted assets.

- Nonprofit organizations seeking new funders will have a difficult time. In the wake of the downturn, many foundations made their grant review processes more selective, moved to a practice of not accepting unsolicited proposals, made multi-year commitments to a set of existing core grantees, and took other actions that reduced the likelihood that organizations new to the foundation could receive funding. This is an indicator that, unless the overall funding available for social justice work is increased significantly, nonprofit organizations will have a difficult time acquiring new funders.

- Some foundations are unintentionally depleting their endowments at a very slow rate. At an average (7 percent) rate of return, the assets of eight foundations are projected to decline slightly, with five foundations experiencing decline at a rate of 1 percent to 3 percent each year. The phenomenon of depleted assets in these foundations, and others that have spent more than they earned in the early post-crisis years, may result in reduced grantmaking in the future as they take corrective actions.
While the outcomes of this study are suggestive of the direction of trends in both asset values and grantmaking expenditures for the foundations studied, care should be taken in drawing generalizations because the total number of foundations in the study is small.

The study's results do, however, offer guidance to endowed foundations in three key areas. First, they point to the importance, particularly in today's uncertain economy, of undertaking regular financial analysis that incorporates future asset and grantmaking projections (reflecting different market assumptions) and assists in planning ahead for the effects of both large and small endowment fluctuations. They also reinforce the need for regular and timely communication of foundation strategy, including both large and small changes, to grantees, peers, and the broader fields in which foundations are active. Finally, they highlight actions, such as providing intensive financial management and resource development assistance to grantees, that foundations might consider taking even in good economic times.

Recommendations for further inquiry include tracking the actual experience of funders in this study through 2015, as well as beginning to assess the impact of the crisis on public foundations, corporate foundations, local foundations, and foundations with annual giving levels above the ceiling of this study. 


\section{Introduction}

In the second half of 2008 , the United States experienced a severe economic downturn. Often called the Global Financial Crisis, it is considered by many economists to be the worst financial crisis since the Great Depression. In the U.S., the effects of the downturn were felt across every sector of our economy and society.
Philanthropy was, of course, no exception; according to Foundation Center data, in 2008, U.S. foundation assets declined a record 17.2 percent.

Despite some recovery in the stock market, the 2008 downturn continues to impact philanthropic giving negatively. Many endowed foundations base their annual giving calculations on multiple yearly, quarterly, or monthly averages of asset values. This year (2011), the 2007 asset levels drop out of the "trailing average," leaving only the postdownturn asset level years of 2008-2010, resulting in further reductions in grantmaking. In addition, the August 8 drop in the Dow Jones Average of over 600 points following the downgrade of U.S. debt, and the extended volatility in the market, affected foundation portfolios. Such volatility, uncertainty, and unpredictability are today's "norm," and will affect endowments and grantmaking levels for many years into the future. This is the context in which foundation executives, boards of directors, and their financial managers and advisors are considering possible scenarios and making decisions about current and future investment strategies, payout amounts, and grantmaking levels.

In the arena of social justice philanthropy (see BOX), which spans multiple areas of activity, from human rights to environmental justice to the arts, giving among funders sampled in the Foundation Center's Key Facts on Social Justice Grantmaking contracted from $\$ 3.7$ billion in 2008 to $\$ 3.1$ billion in 2009 . This was particularly unfortunate because social justice funding had been trending upwards during the first half of the decade. A Foundation Center study released in 2009 reported that social justice funding grew faster than overall giving between 2002 and 2006 and noted a sense of optimism for the future with the start of the Obama administration.

Several factors indicate that social justice funding was disproportionately impacted by the 2008 downturn and will be disproportionately impacted by further volatility and uncertainty in the stock market. First, there are a limited number of funders in the field, and those foundations that devote their entire grantmaking to social justice have relatively small portfolios. Second, those foundations for which social justice giving represents a portion of total giving face decisions about strategy, at a time when public funds meant to meet basic human needs are under continued attack. In addition, several social justice funders have recently spent down their assets, permanently leaving the field, or are in the spend-down process (e.g., The Atlantic Philanthropies, FACT, Beldon Fund, Solidago, Quixote Foundation). One of these, The Atlantic Philanthropies, granted over $\$ 400$ million in 2009 in the United States; these substantial resources, however, are not counted in any studies of U.S. social justice philanthropy because Atlantic is not a U.S. foundation.

Turning to the nonprofit organizations that seek and receive social justice funding reveals additional reasons for concern. Many of these groups are small communitybased and member-led organizations working on behalf of the most vulnerable people in marginalized communities across the country. They play a crucial role by focusing on systems change that can have a beneficial impact on hundreds of thousands of people. Typically, however, they have a small, dedicated funder base and are therefore very vulnerable to shifts in social justice funding. In addition, they often lack the capacity to compete with larger nonprofits for public funds or for funding from more "mainstream" foundations as the environment becomes both increasingly competitive (due to scarce resources) and focused on scalability and outcomes. 


\section{PURPOSE OF THE STUDY}

In 2010, concerned that the downturn would impact future levels of funding in social justice philanthropy for years to come, the Cricket Island Foundation (CIF) decided to undertake an analysis of social justice funding through 2015 and to make this vital information available to both grantees and funders. CIF secured a Capstone Team of students from the Robert F. Wagner School of Public Service at New York University (NYU) to conduct the analysis, and reached out to the Social Justice Philanthropy Collaborative (SJPC) for assistance in securing interviews with national funders. Together, CIF and SJPC enlisted the Foundation Center and the National Committee for Responsive Philanthropy (NCRP) as additional partners. The project was managed overall by CIF, while NCRP served as fiscal sponsor.

The study aims to provide new and useful information to both funders and nonprofit organizations seeking funds. In a time of prolonged uncertainty, and in a sector with long-standing barriers to the free flow of information between grantors and grantees, both of these key players in social change need data that indicate recent trends in assets and giving, present future projections, and describe strategies used by foundations to manage the multiple impacts of depleted assets. Foundations active in the social justice arena can use this information to strategize, inside their institutions and with their peers, about ways to bring additional, urgently needed funding to the field. For nonprofits, information like that presented in this report is crucial to their planning, their strategy development, and their ability to weather the storm.

\section{Defining Social Justic Philanthropy}

For the purposes of this report, "social justice philanthropy" is defined as: "The granting of philanthropic contributions to nonprofit organizations based in the United States and other countries that work for structural change in order to increase the opportunity of those who are the least well off politically, economically, and socially" (Social Justice Grantmaking II, The Foundation Center, 2009).

\section{OVERVIEW OF THE REPORT}

After describing the study's methodology, the report examines historical data (from 2005 to 2009) to discover trends in assets, spending, and giving for 54 foundations. It then describes the major strategies used by 23 foundations to cope with depleted assets in the period following the downturn, and presents projections to 2015 for assets and grantmaking levels of 18 foundations. The report concludes with a summary of findings, limitations, and suggestions for further study. 


\section{Design of the Study}

\section{METHODOLOGY}

\section{Drawing the Sample}

Many sizes and kinds of foundations— - private, corporate, and public — engage in social justice philanthropy. This study's sample was drawn from two large data sets of foundations known to be active in the social justice sector. The first, provided by the Foundation Center, included 847 foundations, and the second, provided by Jason Franklin, executive director of Bolder Giving, included 189 foundations.

To narrow the inquiry and draw focused conclusions, the Capstone Team identified a subset of 54 foundations (Appendix A) that:

- Award less than $\$ 100$ million in grants annually;

- Draw their grantmaking dollars principally from an endowment (to provide a basis for financial forecasting); and

- Award grants in at least two geographic areas (see Appendix B) within the United States (to highlight national funding trends).

The study examines secondary, historical data on the assets, spending, giving, and social justice giving of these 54 foundations. Together, these foundations accounted for about one-quarter of all documented social justice giving in 2009. In addition, 18 foundations agreed to provide both quantitative and qualitative information pertaining to the impact of the 2008 downturn, and an additional 5 provided qualitative data only. The 18 foundations providing both quantitative and qualitative data comprise the sample for the projections to 2015 (Appendix C).

\section{Data Sources}

Primary data (for the forecasting sample of 18) were obtained from senior professionals in each of the foundations, through a phone interview (recorded for accuracy), an online survey, and e-mail exchanges. Interviews were conducted by members of the Capstone Team, Sara Gould, and Sheila Aminmadani. Both the interview and the survey followed a similar protocol (Appendix D). Interviewees were informed of the confidentiality agreement (Appendix E) followed by all researchers via e-mail, phone, and online survey.

Secondary data (on the sample of 54), gathered by the Capstone Team, came from 990-PFs, individual foundation web sites, Guidestar, and the Foundation Center (as well as from Foundation Center staff, who provided figures from other Foundation Center studies). 


\section{Historical Data (2005-2009) on Assets, Spending, Giving, and Social Justice Giving}

To learn about the effects of the 2008 downturn on the sample group of 54 foundations, the study examined historical data (2005-2009) on assets, spending, giving, and social justice giving.

\begin{abstract}
ASSETS
Total assets ${ }^{1}$ of the 54 foundations studied grew steadily from 2005 to 2007 , yet dropped below 2005 levels in 2008 (29 percent drop in 2008, from $\$ 16.7$ billion to $\$ 11.8$ billion) (Figure 1). While 42 of 54 foundations in the sample experienced a partial rebound in assets by the end of 2009, cumulative assets had still not recovered to 2005 levels by this time.
\end{abstract}

The impact of the 2008 financial crisis is evident and universal across the field. All funders experienced an asset loss from 2007 to 2008, with an average percentage loss of 29 percent and average amount loss of $\$ 91.5$ million (Table 1 ).

Foundations in the sample display great disparity in size, from $\$ 1.3$ million to $\$ 1.9$ billion in 2009 assets. Table 2 presents 2009 data on assets for three size groups (large, medium and small); this stratification is used throughout the report.

The data reveal that foundations of diverse asset sizes experienced different asset growth patterns from 2005 to 2009. All three groups experienced similar asset percentage losses in 2008. Large and medium foundations began to experience growth in 2009, while small foundations experienced continued losses (Figures 2 and 3). However, it should be noted that, while the large funders experienced a 6 percent growth after 2008, the group includes three foundations with assets over $\$ 1$ billion. With these three foundations removed, there was virtually no asset growth among large funders $(0.03 \%)$.

\section{SPENDING}

To calculate total expenditures for the 54 foundations in this study, data for 20052008 were obtained from the Trend Tracker Database of the Foundation Center, which calculates expenditures by summing operating and administrative expenses, ${ }^{2}$ contributions, gifts, and grants paid out. ${ }^{3}$ To maintain data consistency, 2009 expenditures were calculated by summing figures from 990-PF reports according to the same formula.

Expenditures increased from 2005 (\$898 million) to 2008 (\$1.1 billion), including an 18 percent jump from 2006 to 2007 . They decreased 15 percent from 2008 to 2009 (\$967 million). Despite the financial crisis, however, expenditures were higher in 2009 than in 2005 (\$898 million) and 2006 (\$911 million) (Figure 4). This is likely due to the fact that many funders made commitments to maintain their grantmaking levels despite depleted assets. In addition, taking inflation into account, the buying power of 2009 dollars was lower than that of 2005 and 2006.

All three size subgroups experienced a significant decrease in expenditures after 2008 (Figures 5 and 6). However, the average spending trend over the full period from 2005 to 2009 differs between the three groups. Despite reducing expenditures after 2008, large funders still spent at a higher level in 2009 than they did in 2005 and 2006. In contrast, after the financial crisis, the expenditures of medium funders dropped below 2006 levels and the expenditures of small funders dropped below 2005 levels. 
Figure 1. Total Assets (millions), 2005-2009

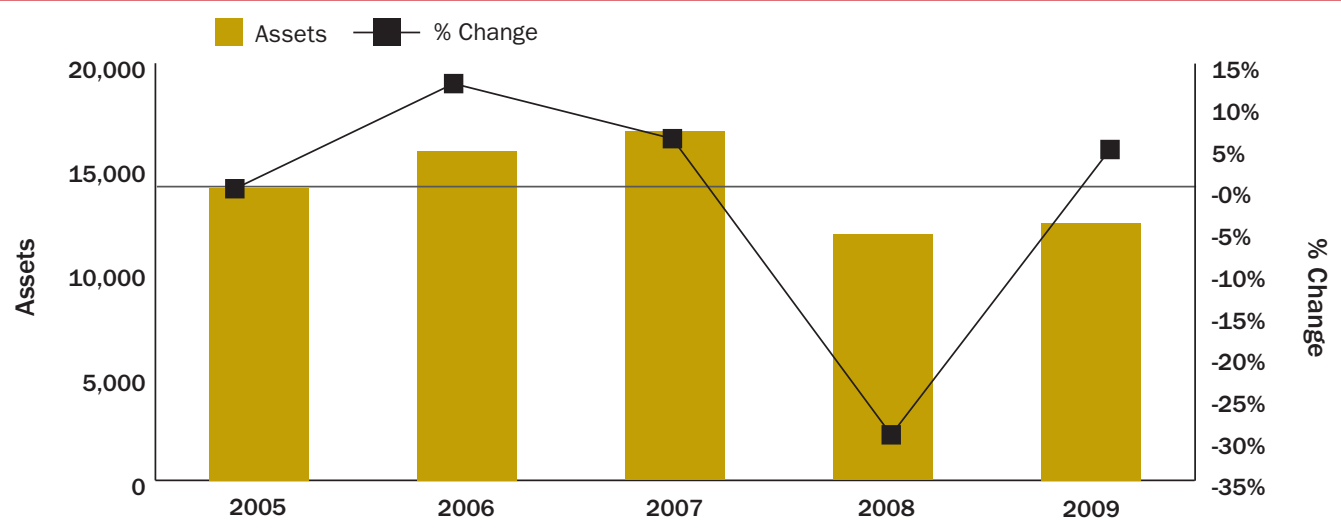

Source: NYC Capstone Team analysis of data from Foundation Center's Trend Tracker and 990-PFs of foundations for 2005 to 2009.

Table 1. Change in Assets from 2007 to 2008

\begin{tabular}{lrrrr} 
& \multicolumn{1}{c}{ Best } & \multicolumn{1}{c}{ Worst* } & \multicolumn{1}{c}{ Mean } & \multicolumn{1}{c}{ Median } \\
\cline { 2 - 5 } Dollar Amount & $-507,261$ & $-734,832,276$ & $-91,467,670$ & $-41,019,561$ \\
Percentage & -0.012 & -0.441 & -0.294 & -0.314
\end{tabular}

*One foundation experienced an 88 percent decrease in assets from 2007 to 2008

because it was giving away the gifts and contributions it received in the previous year.

This foundation was not included in the calculation.
Table 2. Descriptive Statistics of Three Subgroups by 2009 Assets

\begin{tabular}{lcccc} 
& & \multicolumn{3}{c}{ Asset } \\
\cline { 3 - 5 } 2009 Asset & Number & Average & Median & Range \\
\hline $\begin{array}{l}\text { Large Funders: } \\
>\$ 200 \text { million }\end{array}$ & 17 & $\$ 571,651,529$ & $\$ 415,102,143$ & $\$ 207,444,887-$ \\
Medium Funders: & 20 & $\$ 112,709,222$ & $\$ 114,628,921$ & $\$ 51,964,740-$ \\
$\begin{array}{l}\$ 50-\$ 200 \text { million } \\
\text { Small Funders: }\end{array}$ & 17 & $\$ 22,053,164$ & $\$ 23,759,427$ & $\$ 1,295,378$ - \\
$<\$ 50$ million & & & & $\$ 44,534,986$ \\
\hline
\end{tabular}

Figure 2. Average Assets by Size Subgroup (millions), 2005-2009

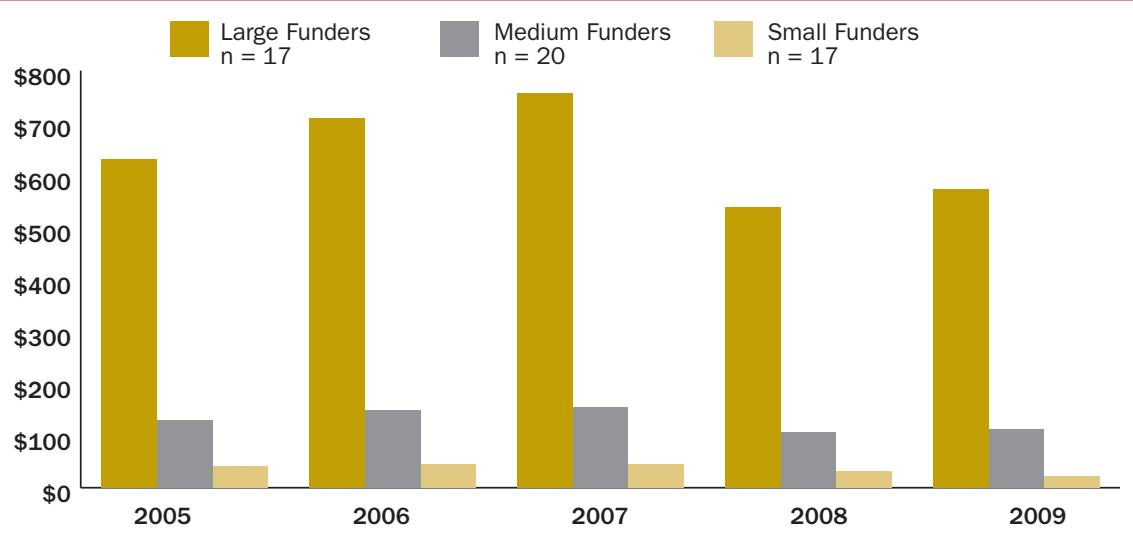

Source: NYC Capstone Team analysis of data from Foundation Center's Trend Tracker and 990-PFs of foundations for 2005 to 2009. 
Figure 3. Percentage Change of Average Assets by Size Subgroup, 2005-2009

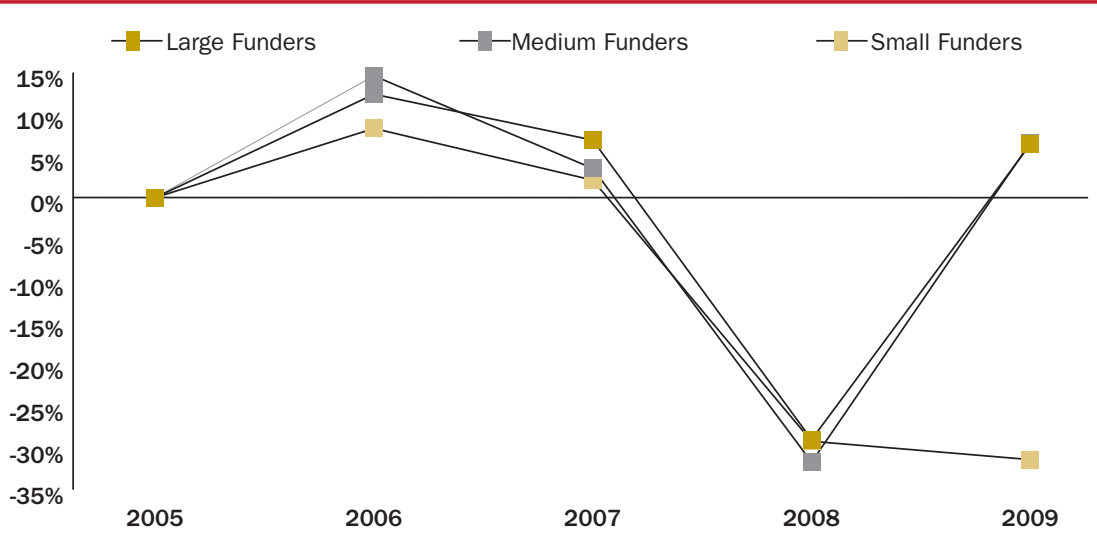

Source: NYC Capstone Team analysis of data from Foundation Center's Trend Tracker and 990-PFs of foundations for 2005 to 2009.

Figure 4. Total Expenditure (millions), 2005-2009

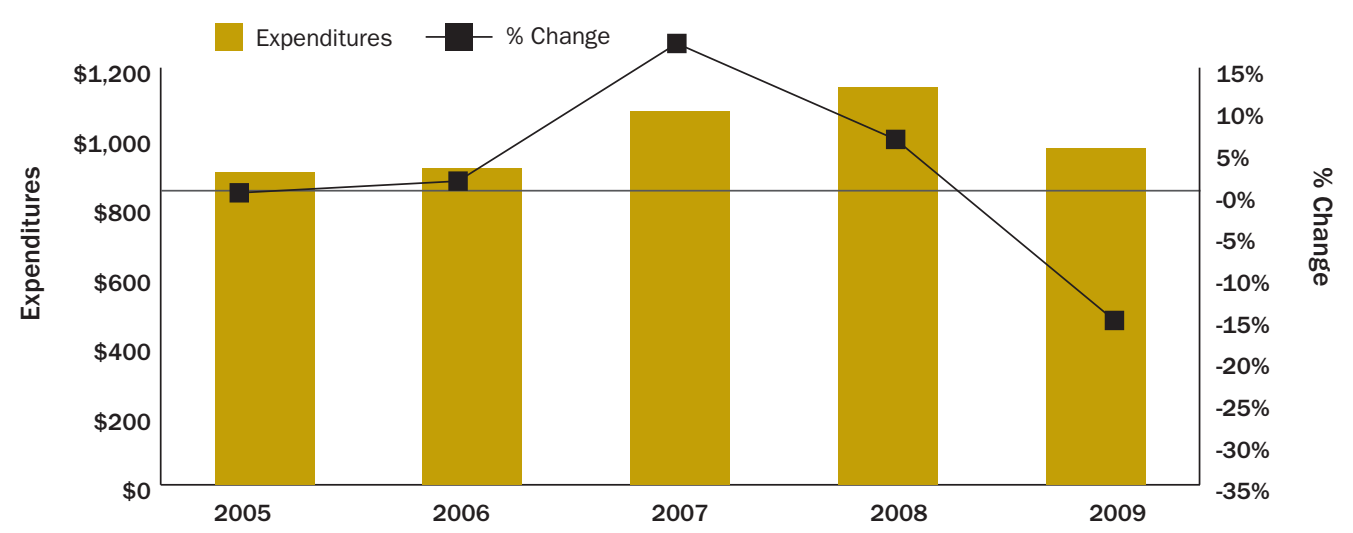

Source: NYC Capstone Team analysis of data from Foundation Center's Trend Tracker and 990-PFs of foundations for 2005 to 2009.

Figure 5. Average Expenditure by Size Subgroup (millions), 2005-2009

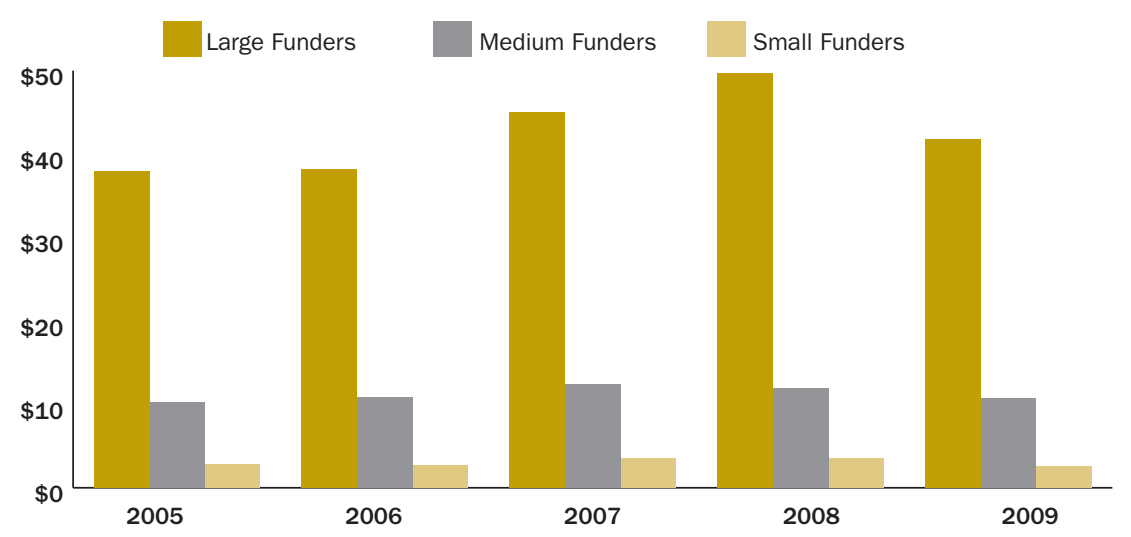

Source: NYC Capstone Team analysis of data from Foundation Center's Trend Tracker and 990-PFs of foundations for 2005 to 2009. 


\section{GIVING}

Cumulative dollar amounts awarded by the 54 foundations in our sample were higher in 2009 ( $\$ 763$ million) than in 2005 (\$657 million), despite a sharp decrease of 19 percent from 2008 to 2009 (Figure 7). In 2009, aggregate giving fell below $\$ 800$ million, lower than 2007 levels. This may be due to the timelagged effect of calculating payout rates by multi-quarters trailing average, which has been discussed previously in the report.
Trends in average giving by size subgroup mirror aggregate trends, with some notable differences (Figures 8 and 9).

Large and medium funders experienced an overall increase from 2005 to 2009 giving levels; small funders saw an overall decrease from 2005 to 2009. All three groups displayed significantly lower giving levels in 2009 than in 2008. Large and medium funders' giving in 2009 was lower than it had been since the start of 2007. Small funders experienced the most volatility during the five years in question, displaying a dip in giving levels between 2005 and 2006, a sharp rise between 2006 and 2007, and a 2009 dip in giving to levels below 2005.

Figure 6. Percentage Changes in Average Expenditure by Size Subgroup, 2005-2009

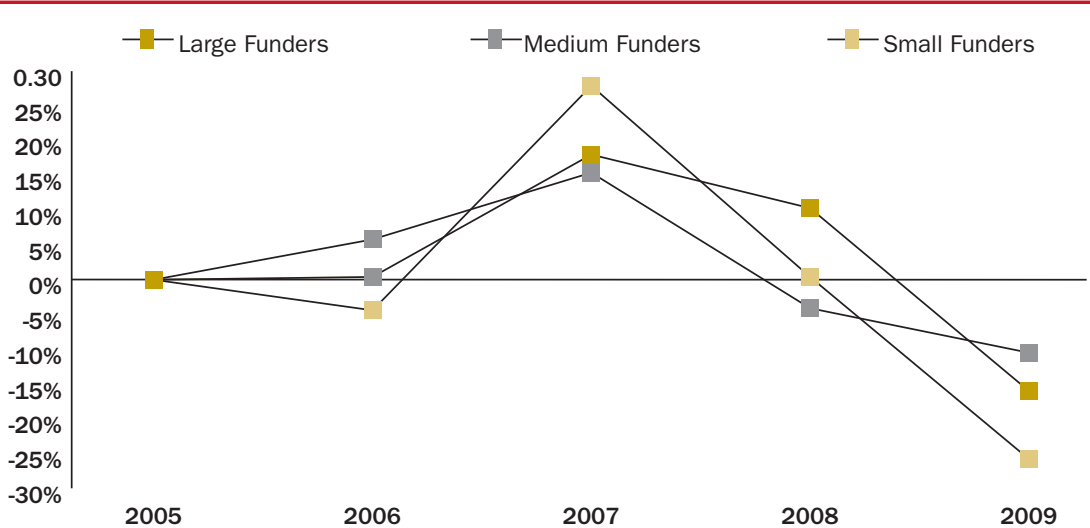

Source: NYC Capstone Team analysis of data from Foundation Center's Trend Tracker and 990-PFs of foundations for 2005 to 2009.

Figure 7. Total Giving (millions), 2005-2009

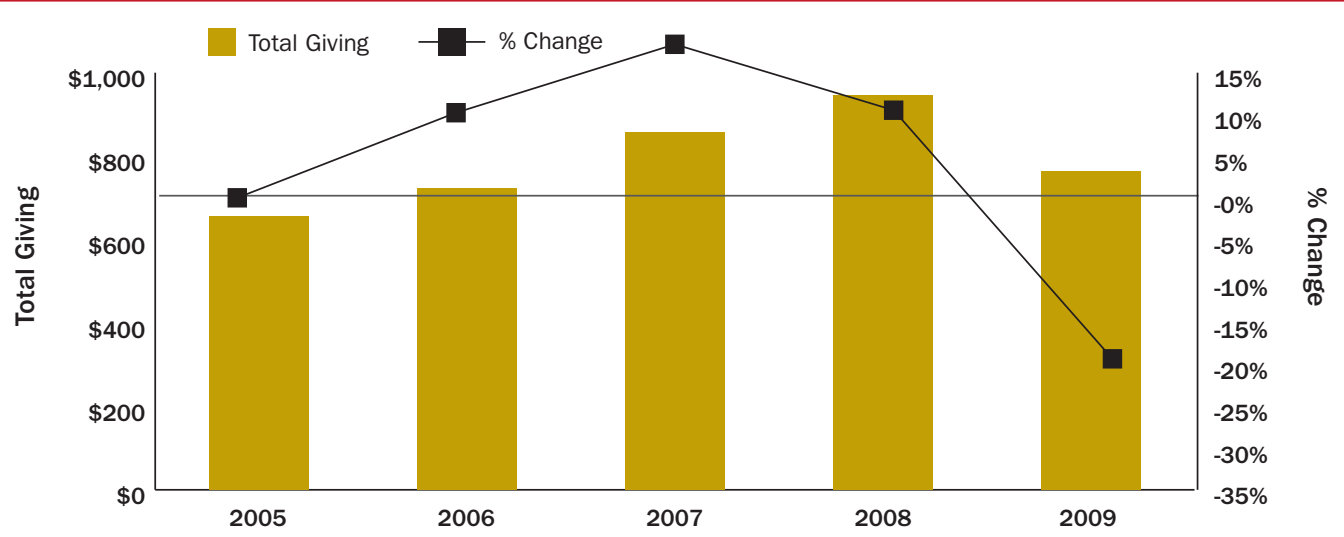

Source: NYC Capstone Team analysis of data from Foundation Center's Trend Tracker and 990-PFs of foundations for 2005 to 2009. 


\section{GIVING/TOTAL EXPENDITURES}

Giving relative to total expenditures decreased from 2008 (83 percent) to 2009 (79 percent) mainly because the crisis adversely impacted the composition of spending. Although giving as a percentage of total spending was overall higher in 2009 than in 2005, it dropped nearly four percentage points from 2008 to 2009, a shift to levels not seen since the beginning of 2006 (Figure 10). Decreases in expenditures, and in giving as a percentage of spending, do not occur until 2009, implying that the effects of the 2008 financial downturn are only beginning to be felt.
Similarly, the giving-to-spending ratio differs between size subgroups (Figure 11). Large and medium funders typically spend more on giving than small funders do, perhaps as a result of operational efficiencies. In this study, both large and small funders decreased their giving-to-spending ratio after 2008, with large funders falling to a level below the 2006 level, and small funders falling to a level well below 2006.

Figure 8. Average Giving by Size Subgroup (millions), 2005-2009

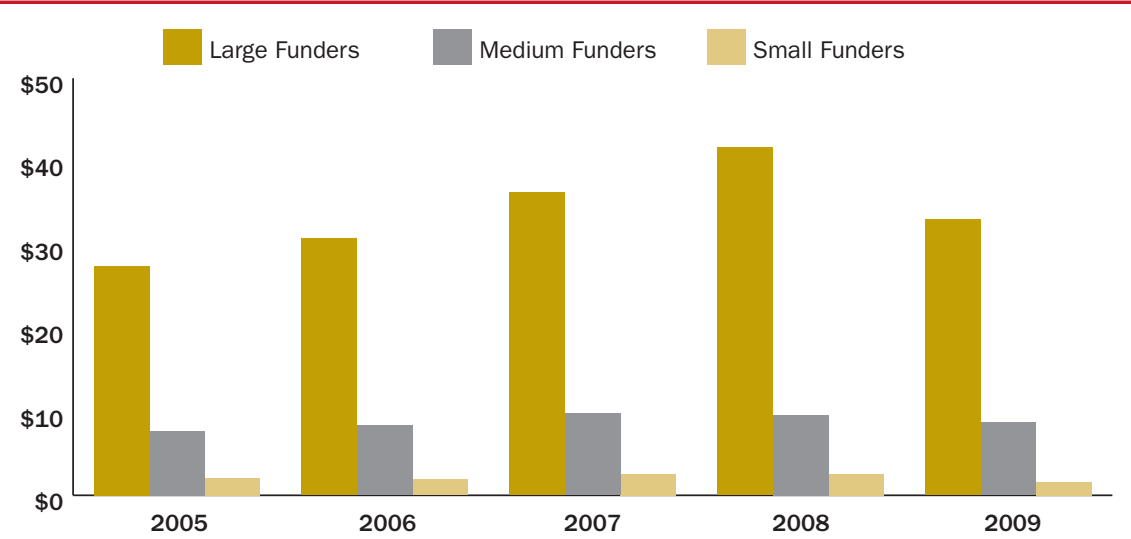

Source: NYC Capstone Team analysis of data from Foundation Center's Trend Tracker and 990-PFs of foundations for 2005 to 2009.

Figure 9. Percentage Change of Average Giving by Size Subgroup, 2005-2009

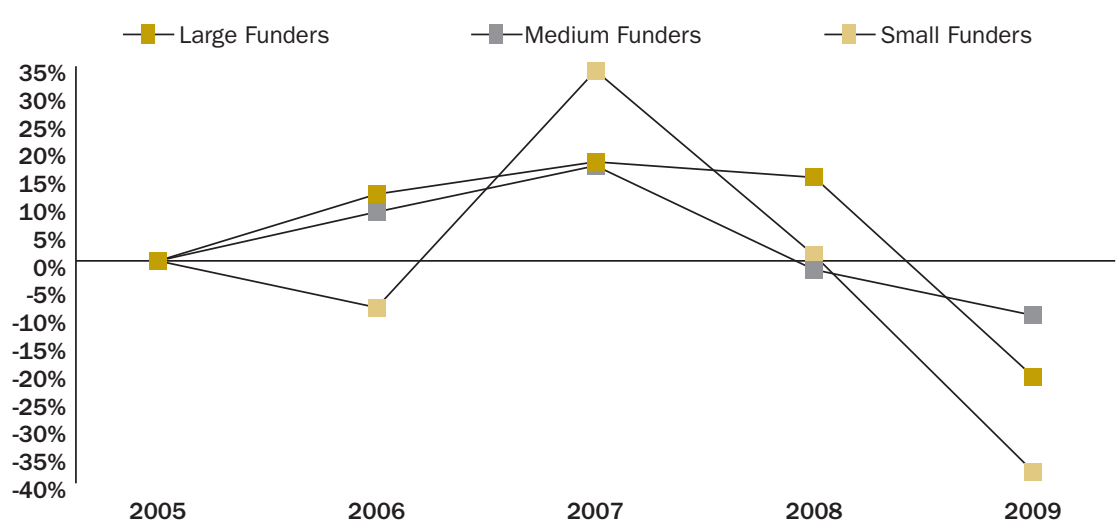

Source: NYC Capstone Team analysis of data from Foundation Center's Trend Tracker and 990-PFs of foundations for 2005 to 2009. 
Figure 10. Giving/Expenditure Ratio (millions), 2005-2009

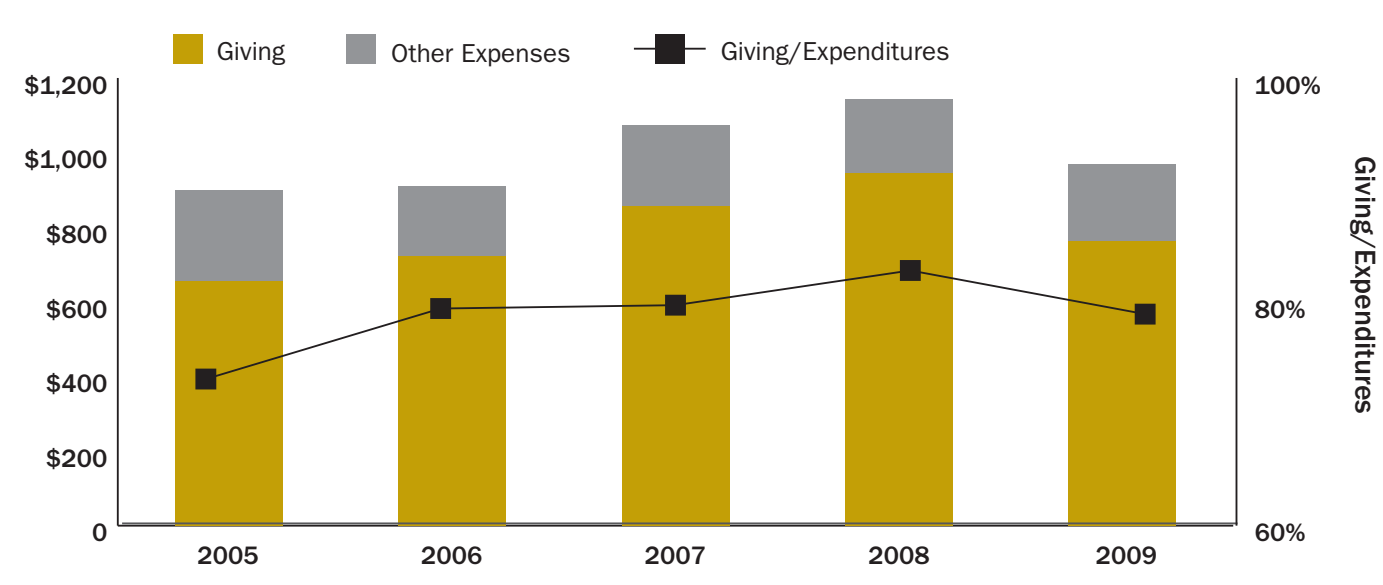

Source: NYC Capstone Team analysis of data from Foundation Center's Trend Tracker and 990-PFs of foundations for 2005 to 2009.

Figure 11. Giving/Expenditure Ratio by Size Subgroup, 2005-2009

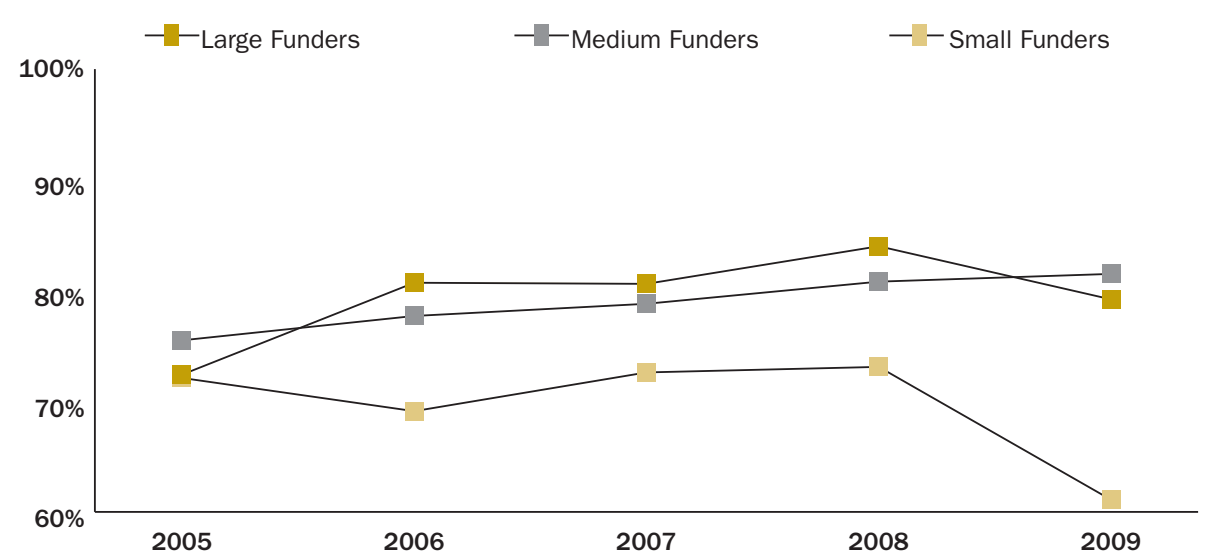

Source: NYC Capstone Team analysis of data from Foundation Center's Trend Tracker and 990-PFs of foundations for 2005 to 2009.

Figure 12. Average Percentage of Social Justice Giving of Entire Sample

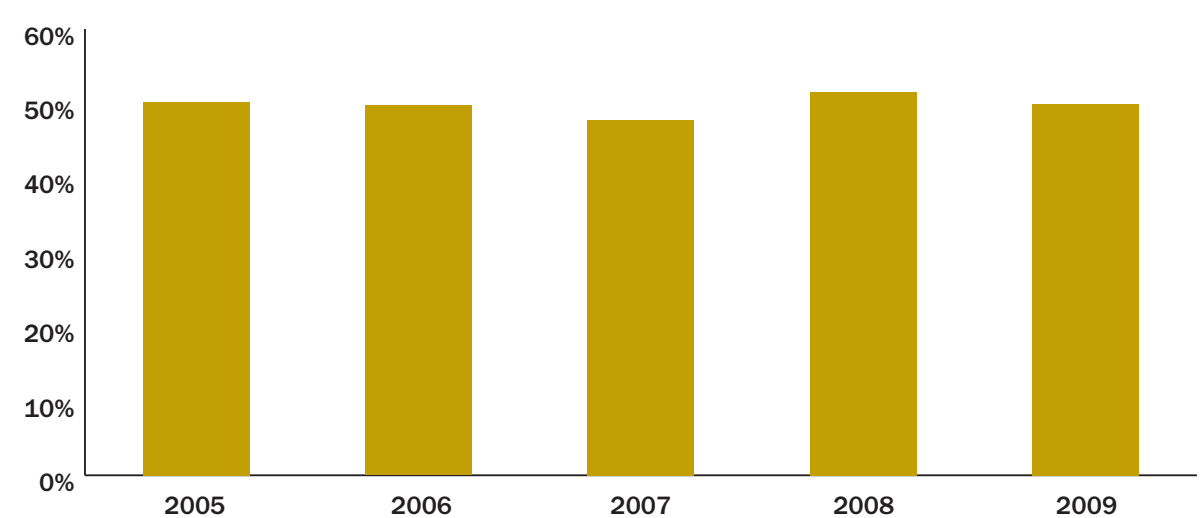

Source: NYC Capstone Team analysis of data from Foundation Center's Trend Tracker, 990-PFs, and phone interviews. 


\section{SOCIAL JUSTICE GIVING AS A PERCENTAGE OF TOTAL GIVING}

The aggregated average percentage of social justice giving varied only slightly during the period 2005 to 2009

(Figure 12), hovering around 50 percent.

An examination by size subgroups (Table 3) confirmed that fluctuations in social justice giving as a percentage of total giving have been minimal over the past five years for all sizes of foundations. Large funders experienced a slight overall decline in the percentage of social justice giving from 2005 (42 percent) to 2009 (39 percent), while medium funders displayed a slight overall increase. Small funders' percentage of social justice giving was relatively unchanged.

Social justice giving was calculated using the definition of social justice philanthropy highlighted earlier in the report. The Foundation Center provided figures for the majority of funders in the sample. For the remainder, social justice giving percentages were obtained from one of the following formulae:

- An application of the definition of "social justice philanthropy" to the grants list on the foundation's most recent 990-PF form; or

- Qualitative data from phone interviews.

Because of diverse data sources, the social justice giving percentages are estimates.
Table 3. Average Percentage of Social Justice Giving by Subgroup

\begin{tabular}{lccc} 
& \multicolumn{3}{c}{ Subgroup } \\
\cline { 2 - 4 } Year & Large & Medium & Small \\
\hline 2005 & $42 \%$ & $38 \%$ & $73 \%$ \\
2006 & $38 \%$ & $39 \%$ & $74 \%$ \\
2007 & $35 \%$ & $37 \%$ & $73 \%$ \\
2008 & $37 \%$ & $40 \%$ & $80 \%$ \\
2009 & $39 \%$ & $39 \%$ & $73 \%$ \\
\hline
\end{tabular}

\section{Endnotes}

1. Data are obtained from Line I of the 990-PF: fair market value of all assets at end of year. For some foundations with 990-PFs not filed for certain years, average numbers are used to substitute the missing values. The same treatment is applied to the unavailable data in expenditures and giving in the later sections.

2. Line 24 , column (a) of $990-\mathrm{PF}$, on accrual basis.

3. Line 25 , column (c) of 990-PF, on cash basis. 


\section{Foundation Strategy in the Immediate Aftermath of the Downturn}

In phone interviews designed

to gather both quantitative and

qualitative information from

23 foundations, senior foundation

officials were asked to identify

differences that could be attributed

to the immediate aftermath of the

economic downturn in the areas of

grantmaking strategy and assets.
In the area of grantmaking strategy, interviewee responses about their actions immediately following the downturn revealed a range of approaches, as they devised ways to:

- Maintain current grantmaking levels;

- Provide assistance to current grantees; and

- Adapt their grantmaking strategy for the future.

First, nearly every foundation interviewed reported a goal, in the immediate wake of the downturn, of maintaining current levels of grantmaking despite depleted assets. Payout rates became a secondary consideration, and most reported that they changed their payout policies to preserve grantmaking levels. Interviewees noted that maintaining grantmaking levels was such an important goal because it preserved their impact, even during a time of crisis. In fact, four interviewees report that in 2011 and beyond they plan to increase their grantmaking allocations.

To achieve the goal of maintaining their grantmaking level, foundations found ways to reduce other costs (e.g., decreasing staff, administrative, and other costs) and maximize resources. Many made the decision to change their personnel configuration, either by laying off existing staff, not filling open positions, or eliminating consultants.

Interviewees used a variety of other strategies to further reduce operating costs after 2008. A few changed their office space by giving up or subleasing portions of the space. Most spent less on expenses related to their board of directors, spending less on board meetings by shortening them and/or changing their location. Additionally, foundations changed their health and other insurance plans to cut costs, reduced or eliminated contributions to pension plans, limited travel for staff members, and implemented salary reductions and/or freezes.

Second, nearly every foundation provided as much support as possible to its current grantees. Every foundation made a concerted effort to maintain open lines of communication with its grantees. In doing so, they aimed both at learning about the kinds of assistance that would be most beneficial to these organizations, and at informing grantees about the immediate impacts of the downturn on the foundation's upcoming grantmaking. Interviewees used a variety of ways to communicate, including surveys, one-on-one conversations, and gathering grantees in small groups.

To create greater flexibility for grantees, foundations allowed (and often encouraged) them to reprogram current grant dollars, granting permission to spend restricted program grants on unrestricted costs. Many foundations actively attempted to leverage their own dollars by identifying additional funders for their grantees and making introductions and connections. Additionally, since the 2008 crisis, some interviewees have contracted with consultants for individualized financial management training and/or fundraising and development assistance for core grantees.

Third, in adapting their current grantmaking strategy for a very different financial environment, interviewees addressed a range of issues. Several took actions that strongly benefitted current grantees, including: 
- Adopting a closed RFP process (not accepting unsolicited proposals);

- Creating an overall more selective grant review process, reducing the likelihood that organizations new to the foundation will become grantees;

- Remaining active in the geographic areas where they had an established presence, and remaining committed to existing issue areas and approaches;

- Making multi-year grants to core partner organizations; and

- Facilitating grantee collaboration, including providing opportunities for networks to develop between and among people doing work in similar areas.

Other adaptations did not benefit current grantees. For example, a few foundations ended long-standing program areas. Some began to change the profile of organizations that they fund, favoring larger, more mature and stable groups connected to larger efforts or national campaigns. Some decided not to continue awarding multi-year grants, or reduced their definition of multi-year from three years to two. Finally, many reported that they are scrutinizing grantee impact even more closely than in the past.

The interviews also revealed that, prior to the downturn, most of the foundations engaged in some form of regranting, making grants (for the purpose of regranting) either to single organizations or to funding collaboratives. For the most part, the downturn did not change their use of such regranting strategies.
In the area of assets, interviews revealed that only one foundation is actively engaged in fundraising to increase its assets, focusing internally on its donor family and board of directors. If successful, the foundation anticipates that a portion of the capital raised would be added to its endowment, while the remainder would augment annual giving.

Interviews also document the involvement of several foundations in using a greater portion of their current assets for mission-related activities, particularly program-related investments (PRIs). Almost uniformly, however, their involvement in PRIs is not related to the economic downturn. The downturn has impacted some existing PRIs; one funder, for example, reported that repayment by a recipient organization has been delayed.

In terms of new mission-related investment activity connected to the downturn, one foundation leader used it as an opportunity to make a case to the board of directors that the investment of the foundation's endowment should follow "a rigorous mission-aligned strategy." The board agreed, and all of this foundation's assets are now in mission-related investments embedded with strong human rights and environmental sustainability values.

Several other foundations echoed this desire to increase mission-related investments in the wake of the downturn, and to partner with other foundations in these endeavors. One foundation would like to pursue shareholder activism, while another would like to create an equity fund to support job development. 


\section{Looking Forward: Projections in Grantmaking Trends and Asset Levels (2008-2015)}

To investigate the future impact of the $\mathbf{2 0 0 8}$ downturn on assets and grantmaking levels, the study undertook a projection analysis to 2015, using information from the 18 foundations that provided both quantitative and qualitative data (Appendix C).
Based on the information gathered from each foundation for this analysis, confidence in the projection fell into three categories:

- High confidence (6 foundations)

- Medium confidence (8 foundations)

- Low confidence (4 foundations)

A description of the criteria for each category is included in Appendix F.

Although there is some uncertainty in the actual numbers, the outcomes of the projection analysis are suggestive of the direction of trends in grantmaking expenditures and asset values. Caution should be exercised, however, in generalizing these findings, as the total number of foundations is small.

\section{METHODOLOGY}

Data for this sample were collected from an on-line survey, interviews, Foundation Center data, 990-PFs, and follow-up phone calls and e-mails.

Projections were made for each individual foundation. Actual asset values were used for the period 2008-2010; projected values were used for the period 2011-2015. Grantmaking expenditures used for 2008 and 2009 were actual, and were projected for the period 2011-2015. 2010 grantmaking expenditures were actual if provided by the foundation, and projected if not. Payout calculation formulas and/or budgeted amounts for grantmaking were provided by each foundation.

To take market performance into account, projections were made using two rates of return - average (7 percent) and below average ( 5 percent). The asset allocations of all but one of the foundations were moderate in risk (60-85 percent equities and/or alternative investments).

Data from 2009 990-PFs provided information on excise tax and investment expense amounts for all of the foundations.

The study uses the following formula (in which annual cash payout is the sum of grantmaking, administrative expense, excise tax, and investment expense) to calculate projected asset values:

MV Assets $=$ Previous year-end asset value +

(Previous year-end asset value * rate of return) + additional income - annual cash payout

\section{CHARACTERISTICS OF FOUNDATIONS IN THE PROJECTION ANALYSIS}

The 18 foundations ranged in size (based on 2009 asset values) from $\$ 4.3$ million to $\$ 464$ million. Grantmaking expenditures in 2009 ranged from $\$ 300,000$ to $\$ 29.7$ million. 
The 18 foundations can be grouped (Figure 13) according to asset size:

- 7 foundations (39 percent) were small foundations $(<\$ 50$ million assets)

- 6 foundations (33 percent) were medium foundations (\$50-\$200 million assets)

- 5 foundations (28 percent) were large foundations (>\$200 million assets)

The outcomes related to small foundations are somewhat skewed because one foundation reported that it is knowingly spending down its assets, with no specific timeline for closure. Projections made using this foundation's current payout formula indicate that spend-down will not be complete before 2015, the end point of this study.

\section{GENERAL TRENDS IN ASSET LEVELS (2008-2015)}

An aggregated analysis of asset values (Figure 14) indicates that, while total asset values surpassed 2008 levels ( $\$ 2.37$ billion) as of 2010 ( $\$ 2.52$ billion), they are projected to remain relatively flat through 2015. From 2008 to 2015, aggregated assets are projected to grow 8 percent. However, from 2011 to 2015 , projected growth, at an average rate of return, is only 0.2 percent to 0.3 percent per year.

Asset growth trajectories among small, medium, and large foundations (Figures 15, 16, and 17) do not vary significantly from each other. They all mirror the aggregate asset values trend, with small foundations slightly worse off than medium and large foundations. Again, in the small foundation group, the foundation that is intentionally spending down pulls down the asset value growth rate. If this foundation is removed, small foundations realize the same small increases each year as medium and large foundations.

To realize flat or slight increases in asset growth, small foundations must spend less on grantmaking, while medium and large foundations can hold steady, or realize increases, in both areas at the same time.

Figure 13. Size Distribution by Number of Foundations in the Sample

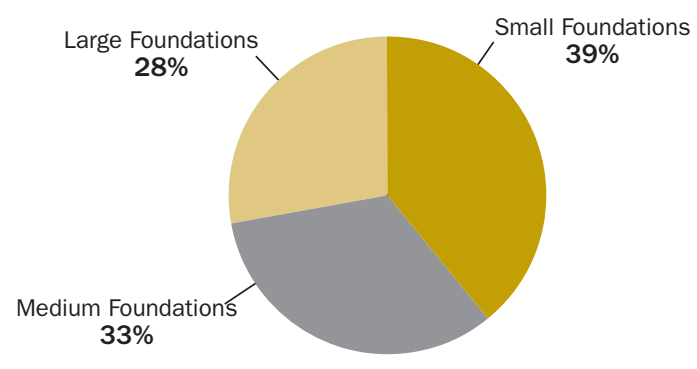

Percent of Foundations

Source: NYC Capstone Team analysis of data from Foundation Center's, 990-PFs, and phone interviews.

Figure 14. All Funders Aggregate Asset Values (millions)

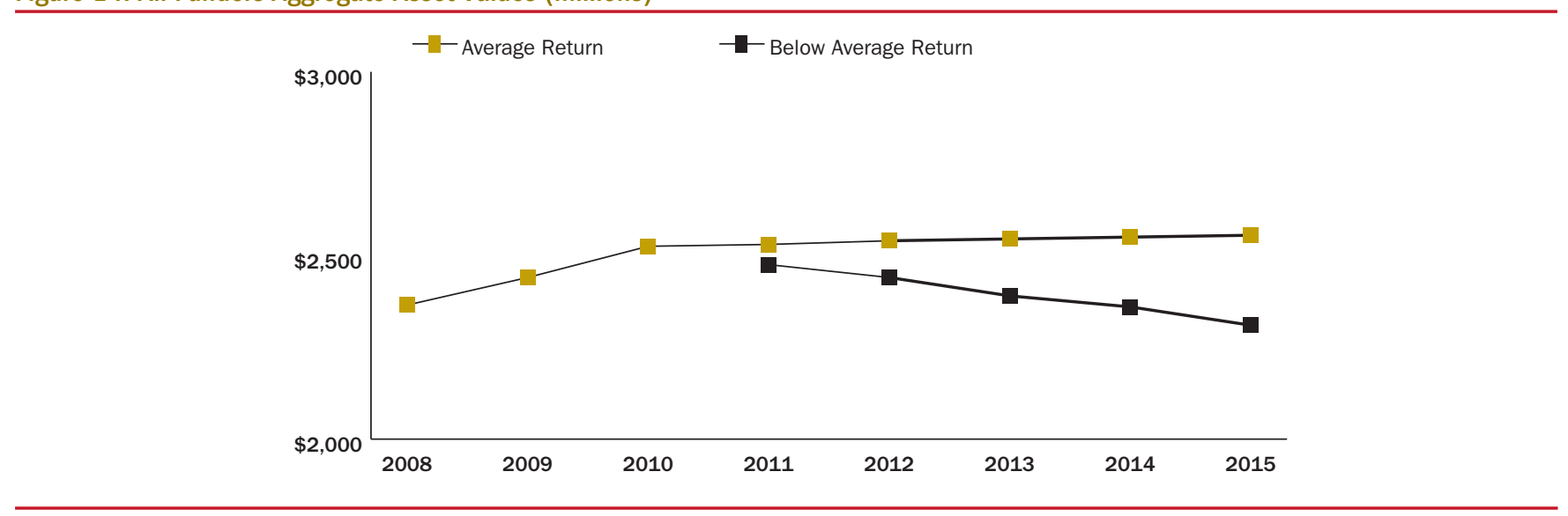


Figure 15. Small Funders $(<50 \mathrm{~m})$ Aggregate Asset Values (millions)

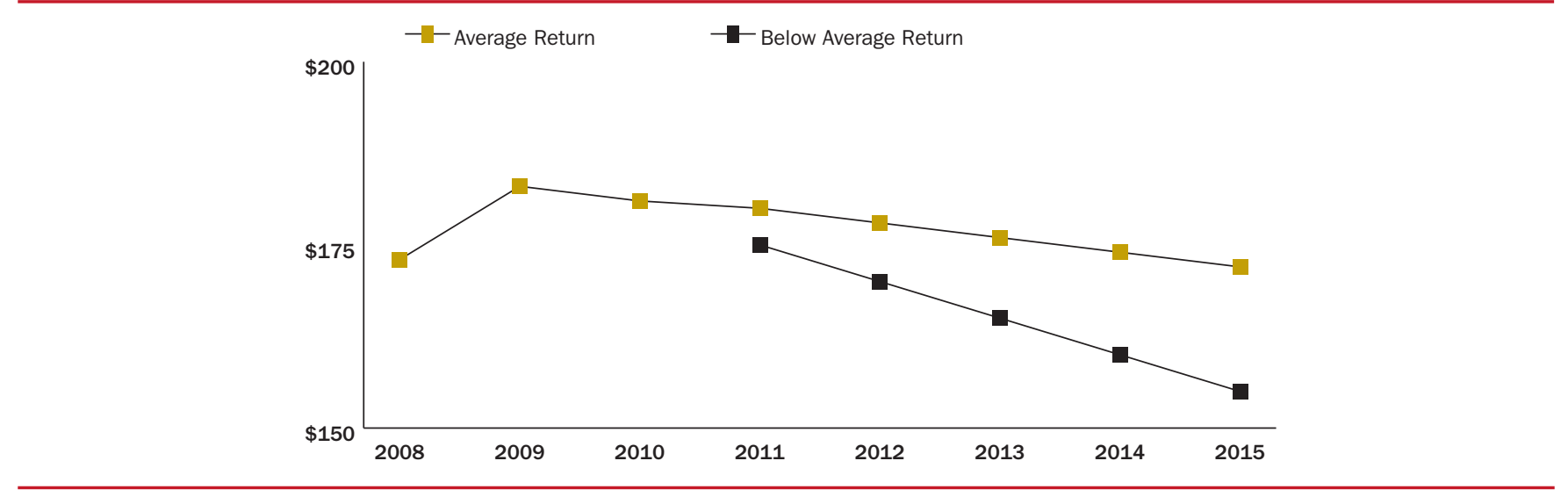

Figure 16. Medium Funders (50-200m) Aggregate Asset Values (millions)

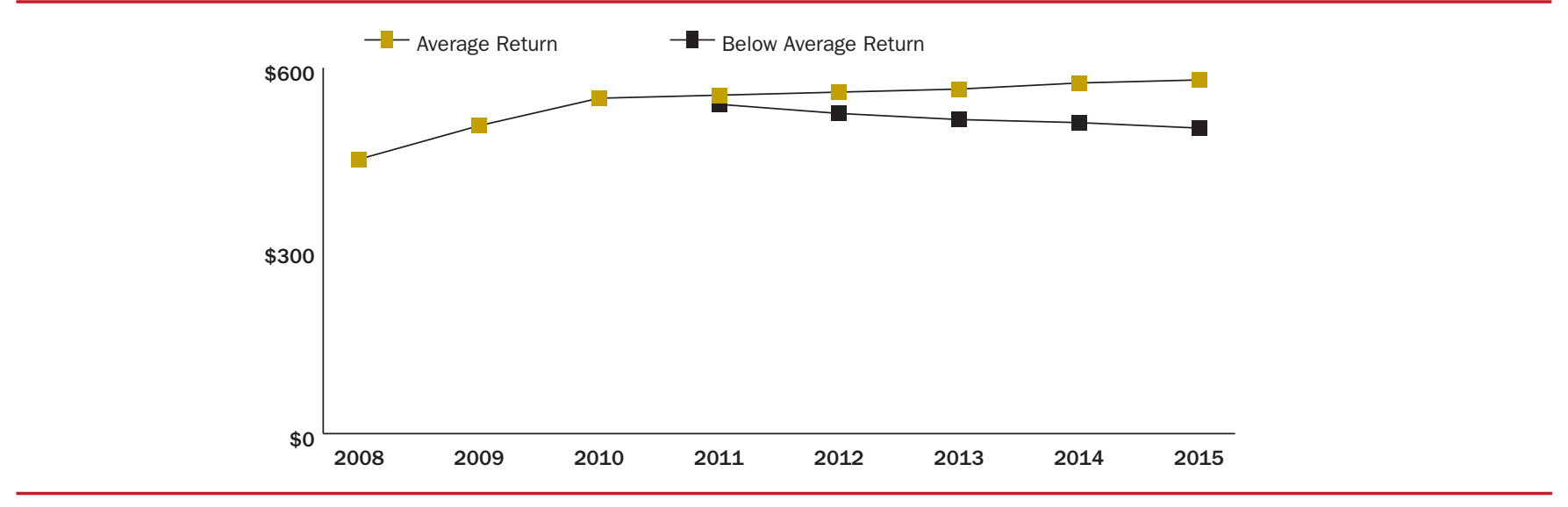

Figure 17. Large Funders (>200m) Aggregate Asset Values (millions)

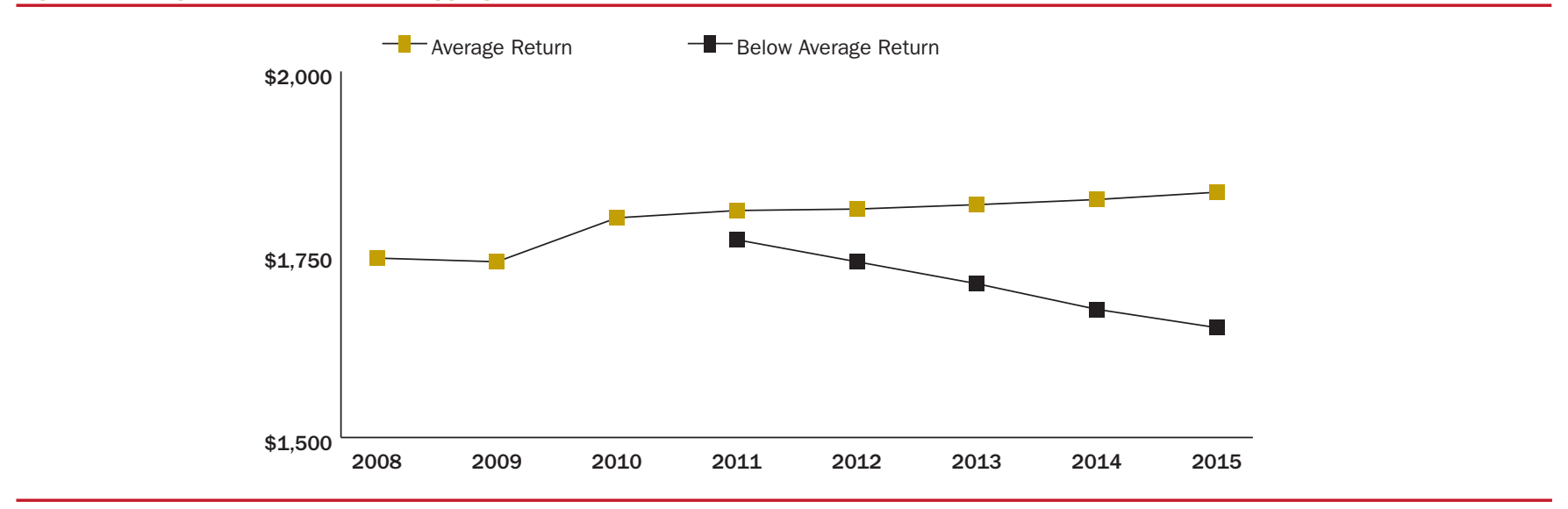


Figure 18. Distribution of the Funders in the Projections of Assets

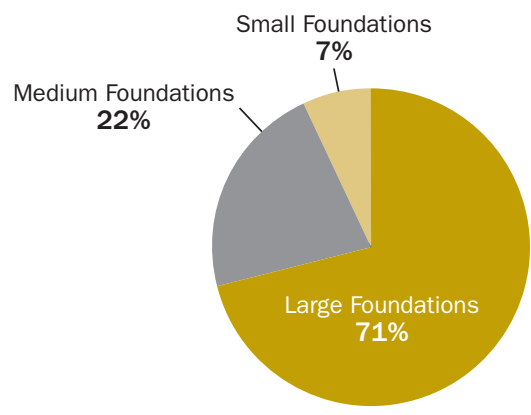

Percent of Foundations

\section{UNINTENTIONAL ASSET DEPLETION}

Only one foundation in the sample indicated that it is intentionally spending down. Yet, at an average rate of return, the projections identify five foundations whose assets are projected to decline 1 percent to 3 percent each year, and another three that are projected to have declines of less than 1 percent each year.

These are very slow rates of asset depletion. As these foundations realize that their asset values have decreased, however, they may take corrective action by lowering their grantmaking expenditures. A mitigating factor is the high percentage of large or medium-sized funders (Figure 18), who can more easily weather small erosions in their assets. If they do take corrective action, however, lowered grantmaking expenditures could adversely impact the projections made in this study.

GRANTMAKING TRENDS (2008-2015)

\author{
General Grantmaking Trends (2008-2015)
}

An aggregate analysis of projected grantmaking expenditures (Figure 19) reveals that grantmaking in 2015 (\$207 million) (at an average rate of return of 7 percent) will be 5.5 percent less than grantmaking in 2008 (\$219 million). In fact, 2008 grantmaking levels will not be seen again during the period covered by these projections.

For these foundations, grantmaking increased in 2010 and, assuming an average rate of return, it is projected to continue increasing in 2011. It is, however, projected to dip slightly in 2012 before gradually increasing through 2015 .

Many foundations reported that while they held their grantmaking levels steady through the economic downturn (2008-2010), they were considering corrections to bring about more sustainable grantmaking levels going forward. In addition, some foundations base their payout calculations on multiple yearly, quarterly, or monthly averages of asset values. Using this methodology, as higher asset values prior to 2008 roll off these averages and are replaced by lower values, grantmaking levels will decrease through 2012.

Finally, of course, grantmaking levels will continue to depend on market performance. For nearly all foundations, an extended period of poor market performance will result in declining grantmaking expenditures.

\section{Effects of Foundation Size on Grantmaking Trends}

When grouped according to size (Figure 23), the analysis of total grantmaking shows that small foundations will continue to struggle through 2015 in their efforts to recover from the economic downturn (Figure 20). At an average rate of return, small foundations are projected to have grantmaking expenditures that are 29 percent less in 2015 (\$9.8 million) than in 2008 ( $\$ 13.8$ million).

Figure 19. All Funders Aggregate Grantmaking (millions)

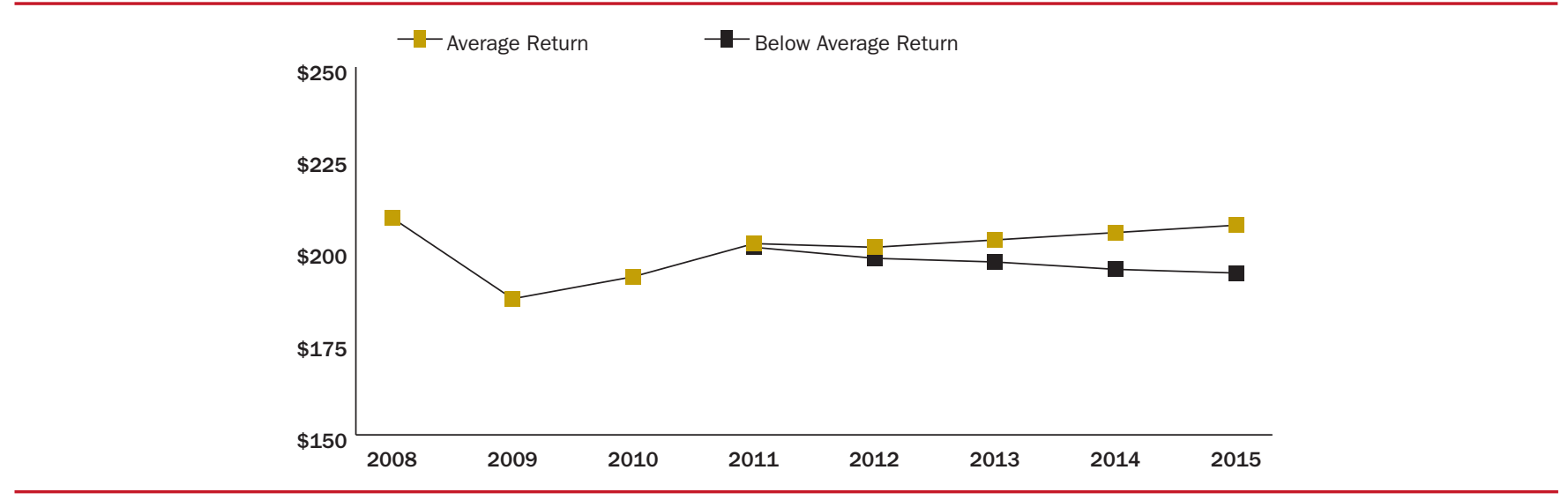


As mentioned earlier, one small foundation reported that it was intentionally spending down, pulling the overall grantmaking levels down. However, even if this foundation is removed from the analysis, small foundations are projected to have grantmaking levels in 2015 that are approximately 17 percent less than 2008, confirming the overall trend.

Given the relatively flat trajectory (for both rates of return) shown in Figure 20 for small foundations, it may be that small foundations will remain small and will need to maintain lower grantmaking levels over the long term.
Medium-sized foundations (Figure 21) are recovering the fastest, and are the only group projected to exceed 2008 grantmaking levels ( $\$ 49.9$ million) by 2015 (\$52.1 million). Their grantmaking grew in 2009 and 2010, but is projected to decrease in 2011 and 2012. Despite this decline, giving by these foundations is projected to stay ahead of or close to 2008 levels and, at an average rate of return, should increase steadily through 2015.

According to the study's projections, large foundations (Figure 22) do not return to 2008 grantmaking levels (\$145 million) by 2015 (\$137 million). Even at an average return, the trajectory is quite flat.

Figure 20. Small Funders ( $<50 \mathrm{~m})$ Aggregate Grantmaking (millions)

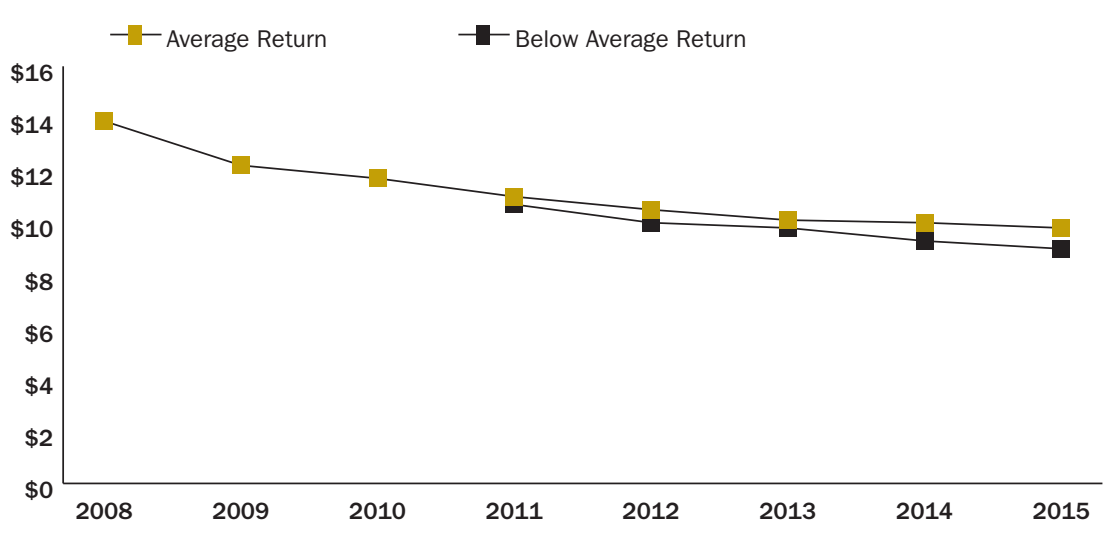

Figure 21. Medium Funders (50-200m) Aggregate Grantmaking (millions)

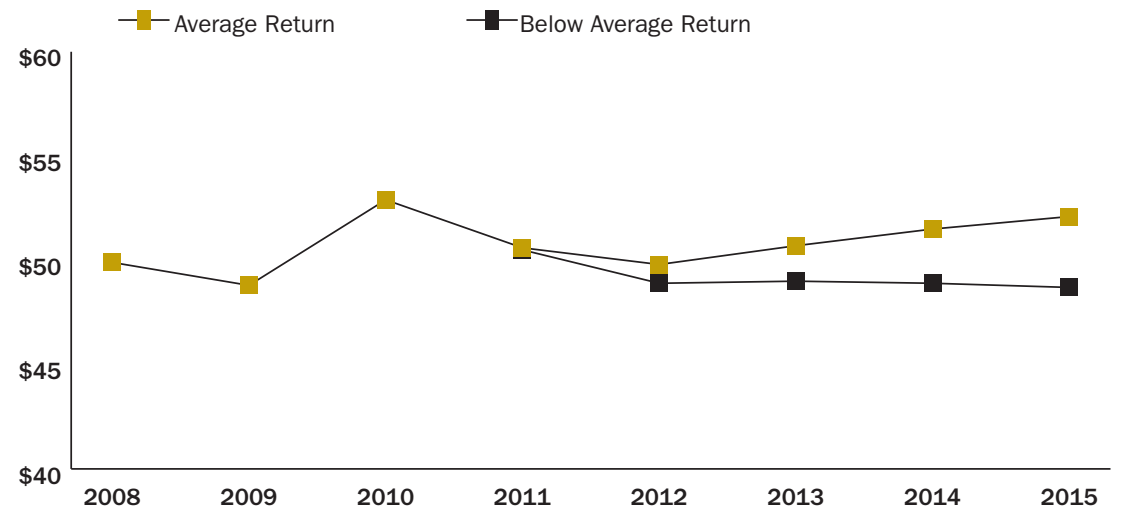


Figure 22. Large Funders (>200m) Aggregate Grantmaking (millions)

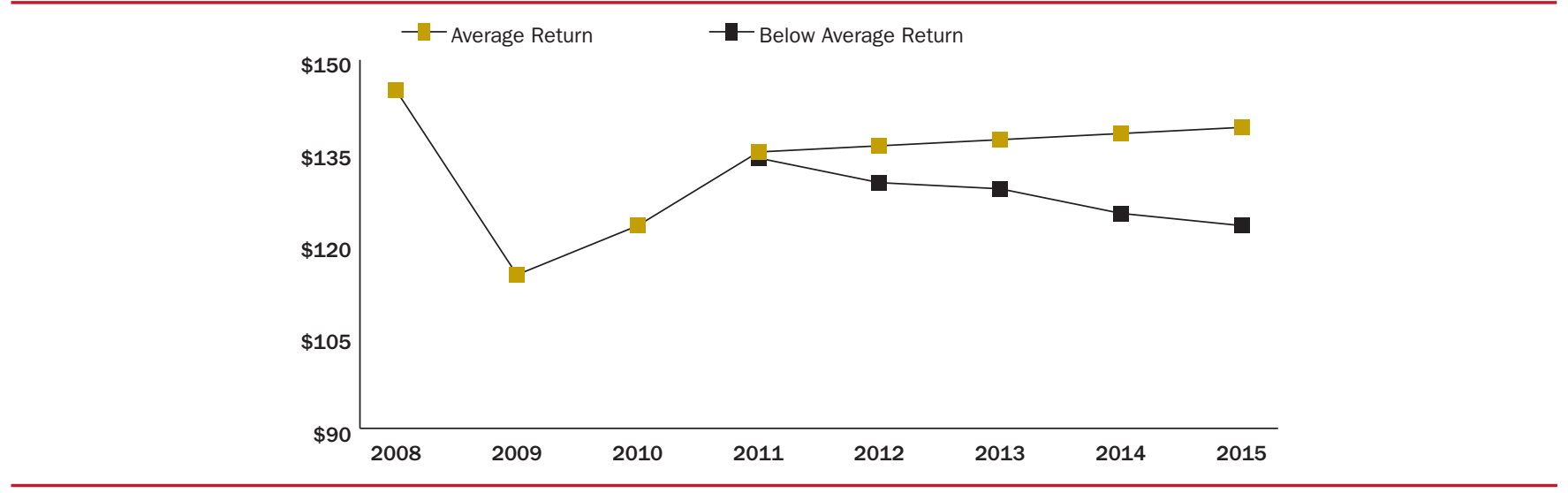

Figure 23. Distribution of the Funders in the Projections of Grantmaking Expenditures

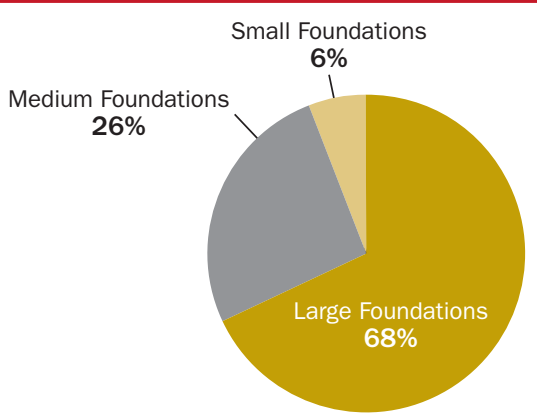

Percent of Foundations 


\section{Conclusion}

\section{FINDINGS}

\section{Key findings of the study indicate that:}

- Unless the field sees five years of above-average investment returns, social justice grantmaking levels in 2015 will remain below 2008 levels. For the subset of 18 foundations, at an average (7 percent) rate of return, grantmaking in 2015 is projected to be 5.5 percent less than grantmaking in 2008. Given the slow economic recovery now underway and the recent volatility and uncertainty in the markets, this finding is particularly worrisome. Also, social justice grantmaking is a portion of total grantmaking for these foundations, and it is not possible to know how their priorities might change with more limited funds.

- Small foundations (less than $\mathbf{\$ 5 0}$ million in assets) will continue to struggle to recover from the economic downturn. At an average (7 percent) rate of return, grantmaking levels of six small foundations studied are projected to be 17 percent less in 2015 than in 2008. Small foundations must spend less in grantmaking to avoid depleting their assets. This finding deserves particular note because of the very heavy reliance on small foundations by local, community-based nonprofits engaged in social justice work.

- In 2009, grantmaking decreased to below 2007 levels, with small foundations experiencing the largest drop. In interviews with 18 foundations, however, senior officials of nearly every one reported taking actions (e.g., increasing payout and decreasing other expenditures) to maintain current grantmaking levels despite depleted assets.

- Organizations seeking new funders will have a difficult time. In the wake of the downturn, many foundations made their grant review processes more selective, moved to a practice of not accepting unsolicited proposals, made multiyear commitments to a set of existing core grantees, and took other actions that reduced the likelihood that organizations new to the foundation could receive funding. Therefore, unless the overall funding available for social justice work is increased significantly, nonprofit organizations will have a difficult time acquiring new funders.

- Some foundations are unintentionally depleting their endowments at a very slow rate. At an average (7 percent) rate of return, the assets of eight foundations are projected to decline slightly, with five foundations experiencing decline at a rate of 1 to 3 percent each year. The phenomenon of unintentional asset depletion in these foundations, and others that have spent more than they earned in the early post-crisis years, may result in reduced grantmaking in the future as they take corrective actions.

\section{RECOMMENDATIONS}

While the outcomes of this study are suggestive of the direction of trends in both asset values and grantmaking expenditures for the foundations studied, care should be taken in drawing generalizations because the total number of foundations in the study is small. 
The study's results do, however, offer guidance to endowed foundations in three key areas. First, they point to the importance, particularly in today's uncertain economy, of undertaking regular financial analysis that incorporates future asset and grantmaking projections (reflecting different market assumptions) and assists in planning ahead for the effects of both large and small endowment fluctuations. They also reinforce the need for regular and timely communication of foundation strategy, including both large and small changes, to grantees, peers, and the broader fields in which foundations are active. Finally, they highlight actions, such as providing intensive financial management and resource development assistance to grantees that the foundation might consider taking even in good economic times.

In addition, the study opens the door for several other pieces of research. First, future research should track the actual experience of foundations in this study. Second, new studies of the continuing effects of the 2008 downturn, and specifically on future amounts of funding available for social justice grantmaking, should focus on a wider group of foundations, including public foundations, corporate foundations, and private foundations that give above the ceiling of those in this study. In addition, the experience of local foundations, in various regions of the country, must be studied because of their important role in sustaining grassroots social justice work.

Interviewees indicated other areas for study, including: 1) whether foundations were adopting recommendations suggested by the National Committee for Responsive Philanthropy (NCRP) concerning best practices in the wake of the 2008 downturn, 2) how mission-related investing might help foundations boost asset levels, 3) how family foundations can promote social justice values in future generations, and 4) whether, and how, social justice funders are aligning their asset investments with their social justice values. 


\section{Appendix A: List of Foundations in Historical Analysis}

- Abelard Foundation - East

- Arcus Foundation

- Blue Moon Fund

- Calamus Foundation

- Colcom Foundation

- Compton Foundation, Inc.

- Cricket Island Foundation

- Eagle Foundation

- Educational Foundation of America

- Edward W. Hazen Foundation

- Evelyn and Walter Haas, Jr. Fund

- FB Heron Foundation

- General Services Foundation

- Gill Foundation

- Hill-Snowdon Foundation

- HKH Foundation

- Howard G. Buffett Foundation

- Hunt Alternatives Fund

- Jessie Smith Noyes Foundation

- John Merck Fund

- Joyce Foundation

- Lannan Foundation

- Levi Strauss Foundation

- Lumina Foundation for Education, Inc.

- Marguerite Casey Foundation

- McIntosh Foundation

- McKnight Foundation
- Merck Family Fund

- Mertz Gilmore Foundation

- The Mitchell Kapor Foundation

- Moriah Fund

- Nathan Cummings Foundation

- Needmor Fund

- Norman Foundation

- Northwest Area Foundation

- NoVo Foundation

- Oak Foundation USA

- Omidyar Network Fund

- Opus Prize Foundation

- Ottinger Foundation

- Overbrook Foundation

- Public Welfare Foundation

- Retirement Research Foundation

- Richard and Rhoda Goldman Fund

- Robert Sterling Clark Foundation, Inc.

- Sandy River Charitable Foundation

- Stephen M. Silberstein Foundation

- Stewardship Foundation

- Surdna Foundation

- Taconic Foundation

- Wallace Alexander Gerbode Foundation

- The Wallace Foundation

- Wallace Global Fund

- WellPoint Foundation 


\section{Appendix B: List of U.S. Geographic Regions as Defined by the Foundation Center}

Source: Foundation Center

foundationcenter.org/gainknowledge/grantsclass/ntee gcs.html

\section{East (region)}

Middle Atlantic (division)

- New Jersey (state)

- New York (state)

- Pennsylvania (state)

New England (division)

- Connecticut (state)

- Maine (state)

- Massachusetts (state)

- New Hampshire (state)

- Rhode Island (state)

- Vermont (state)

\section{Midwest (region)}

East North Central (division)

- Illinois (state)

- Indiana (state)

- Michigan (state)

- Ohio (state)

- Wisconsin (state)

West North Central (division)

- Iowa (state)

- Kansas (state)

- Minnesota (state)

- Missouri (state)

- Nebraska (state)

- North Dakota (state)

- South Dakota (state)

\section{South (region)}

East South Central (division)

- Alabama (state)

- Kentucky (state)

- Mississippi (state)

- Tennessee (state)

South Atlantic (division)

- Delaware (state)

- District of Columbia (national district)

- Florida (state)

- Georgia (state)

- Maryland (state)

- North Carolina (state)

- South Carolina (state)

- Virginia (state)

- West Virginia (state)

West South Central (division)

- Arkansas (state)

- Louisiana (state)

- Oklahoma (state)

- Texas (state)

\section{West (region)}

Mountain (division)

- Arizona (state)

- Colorado (state)

- Idaho (state)

- Montana (state)

- Nevada (state)

- New Mexico (state)

- Utah (state)

- Wyoming (state)

Pacific (division)

- Alaska (state)

- California (state)

- Hawaii (state)

- Oregon (state)

- Washington (state)

\section{Caribbean}

- Puerto Rico

- Virgin Islands of the United States

\section{South Pacific}

- American Samoa

- Guam

- Commonwealth of the Marianas 


\section{Appendix C: Foundations Included in Forecasting to 2015}

- Arcus Foundation

- Compton Foundation, Inc.

- Cricket Island Foundation

- Edward W. Hazen Foundation

- Evelyn and Walter Haas, Jr. Fund

- General Services Foundation

- Gill Foundation

- Hill-Snowdon Foundation

- Merck Family Fund

- The Mitchell Kapor Foundation

- Moriah Fund

- Needmor Fund

- Norman Foundation

- Northwest Area Foundation

- NoVo Foundation

- Ottinger Foundation

- Public Welfare Foundation

- Wallace Alexander Gerbode Foundation 


\section{Appendix D: Interview Protocol}

\section{General changes in wake of financial crisis}

- Staffing

Prompt: e.g., We've cut one person at the associate level.

- Spending Down

Prompt: e.g., We've had conversations about spending down and see it as a strong possibility in the next five years.

- Fundraising

Prompt: e.g., Yes or no

- Other

\section{Assets}

Prompt: e.g., 20 million. Approximate is fine.

- Mar 2008

- Jun 2008

- Sep 2008

- Dec 2008

- Mar 2009

- Jun 2009

- Sep 2009

- Dec 2009

- Mar 2010

- Jun 2010

- Sep 2010

- Dec 2010

- Projected FY 2011 and forward

\section{Spending policy}

- Payout rate

Prompt: e.g., 5 percent of last year's assets, determined at the end of our fiscal year, which is June 30

- FY 2008

- FY 2009

- FY 2010

- Projected FY 2011 and forward
- How assets are calculated for annual payment Prompt: e.g., Ending balance of previous fiscal year, 24-month (2-year) trailing average, 36-month (3-year) trailing average, 60-month (5-year) trailing average, other

- Percentage of annual budget that goes to grantmaking Prompt: e.g., 30 percent to program expenses, 70 percent to grantmaking

- FY 2008

- FY 2009

- FY 2010

- Projected FY 2011 and forward

- Board/staff discretionary giving amount

- Funding that is already committed over next five years

\section{Grantmaking portfolio}

- General changes in strategy

- FY 2008

- FY 2009

- FY 2010

- Projected FY 2011 and forward

- States

- FY 2008

- FY 2009

- FY 2010

- Projected FY 2011 and forward

- Types of organizations

- FY 2008

- FY 2009

- FY 2010

- Projected FY 2011 and forward

- Issues

- FY 2008

- FY 2009

- FY 2010

- Projected FY 2011 and forward 
- Median Size of Grants

- FY 2008

- FY 2009

- FY 2010

- Projected FY 2011 and forward

- Amount of funding that goes to social justice Social justice philanthropy definition: "the granting of philanthropic contributions to nonprofit organizations based in the United States and other countries that work for structural change in order to increase the opportunity of those who are the least well off politically, economically, and socially." (Source: constructed by independent advisory committee, published by the Foundation Center)

Prompt: e.g., 20 percent of funds go to social justice spending

- FY 2008

- FY 2009

- FY 2010

- Projected FY 2011 and forward

\section{Other}

- Return target Prompt: e.g., 4 percent, 6 percent (preferred) OR e.g., conservative (3 to 5 percent), moderate (5 to 8 percent), aggressive (8 to 12 percent) (backup)

- Any expected new contributions to the endowment

- Giving to regranting institutions or funding collaboratives (if applicable)

Prompt: e.g., 20 percent of funding goes to regranting institutions, 10 percent to funding collaborative

- Program-related investments (if applicable) Prompt: e.g., We have PRIs totaling 250k. We expect to be repaid in 2012, and to use that funding for more PRIs.

- Any other questions we should have asked 


\section{Appendix E: Confidentiality Statement}

\begin{tabular}{|l|l|}
\hline Interviewer & \\
\hline Interviewee (use number ID) & \\
\hline Date & \\
\hline
\end{tabular}

Introduction: <Briefly discuss purpose of project and deliverables-the below is an example>

Thanks for taking the time to speak with me today. I am (insert name here), and I am a student at the Robert F. Wagner School of Public Service at NYU. I'm part of a group of students at NYU partnering with the Foundation Center to assess the impact of the financial crisis on the social justice field, capture emerging strategic changes, and forecast future grant distributions. Other partners in this work are the Cricket Island Foundation (a social justice funder focused on youth organizing and based in NYC) and the Social Justice Philanthropy Collaborative (a network of national social justice funders). The end goal of the project is to publish a report that will be administered to social justice and other funders that presents key findings about the effects of the crisis and tries to assess possible future impacts. The report will also help social justice grantees get a better sense of what funding will look like over the next few years, so that they can prepare themselves for any changes.

Confidentiality Statement: (This statement will appear in the e-mail sent to the interviewee, and will also be read aloud at the beginning of the interview).

This interview is one part of our data gathering process, and its specific purpose is to understand how the financial crisis has affected both recent funding and future strategies for funding. This interview should take about 45 minutes, and you may refuse to answer any question for any reason.

Any information provided in this interview will be shared with two people outside of the NYU Capstone Team. The first is our research partner at the Foundation Center, Sara Gould, a senior research fellow, and former ED of the Ms. Foundation. She will be writing the final report. The second person is our project coordinator, Sheila Aminmadani, who works for the Social Justice Philanthropy Collaborative. Information to be published in the final report, or any intermediate report, will not cite you or your foundation specifically; however, the citation may include potentially identifying characteristics such as asset size, annual distributions, and scope. Your foundation will be listed by name in a survey participant list. We will be recording this interview in order to ensure the highest level of accuracy, but only the Capstone Team, Sara Gould, and Sheila Aminmadani will have access to our conversation records.

If you are ok with this, we can begin. 


\section{Appendix F: Criteria for Confidence Categories}

1. High Confidence-The foundation follows a very specific payout policy based on an average of asset value or a year-end asset value, and including formulas for both grantmaking and administrative expenditures. Those formulas were used to calculate grantmaking and administrative expenditures for each year through 2015 . Alternatively, a foundation could fall into this category if it provided its own projections for spending and yearend asset values through 2015. Six (6) foundations are in this category.

2. Medium Confidence-The foundation followed a payout formula using some definite information, but other information lacked specificity or certainty, and required making assumptions. For example, uncertain future contributions, lack of detail on how the administrative budget is calculated, or lack of detail on the asset base used to calculate payout were all situations requiring assumptions. Eight (8) foundations are in this category.

3. Low Confidence-The foundation does not follow a payout policy, but makes payout decisions at the end of each year, and/or the foundation's data lacked specificity or had inconsistencies that required making large assumptions. In these cases, historical payout from 2008 to 2010 was analyzed, and educated guesses were made as the basis for projections through 2015. Four (4) foundations are in this category. 
